\title{
MARTIN LERCHER
}

\section{Wie Bakterien an neue Gene kommen und was sie damit machen}

\section{Evolution auf molekularer Ebene}

„Nichts in der Biologie ergibt Sinn - außer im Licht der Evolution“ (,Nothing in Biology makes sense except in the light of evolution") hat - etwas überspitzt - der Biologe Theodosius Dobzhansky (1900-1975) gesagt. Um zu verstehen, warum Lebewesen so sind wie wir sie (und uns selbst) vorfinden, müssen wir deshalb verstehen, nach welchen Mustern evolutionäre Veränderungen stattfinden. Seit Darwin haben Wissenschaftler beobachtet, wie sichtbare Ausprägungen der Eigenschaften von Organismen sich zwischen verwandten Arten (und den Fossilien ihrer Vorfahren) unterscheiden. In vielen Fällen ist es möglich, einen Zusammenhang zwischen solchen „großen“ evolutionären Veränderungen und Überlebens- beziehungsweise Fortpflanzungsvorteilen (das heißt der Fitness) aufzuzeigen.

Wie aber kommen evolutionäre Veränderungen zustande? Vererbbare Eigenschaften müssen als Erbinformation gespeichert werden. Dies geschieht in der Regel durch ihre Codierung im Genom, einer komplizierten Bibliothek aus Bauplänen und Aufbauanleitungen, deren Details wir nur ansatzweise verstehen. Kleine Veränderungen in der $\mathrm{Zu}$ sammensetzung (der „Buchstabenfolge“) des Genoms können dramatische Auswirkungen haben, etwa wenn ein Enzym plötzlich in einem völlig neuen Zusammenhang aktiviert wird. Aufgrund unseres beschränkten Wissens sind diese Auswirkungen in der Regel aber nicht vorhersagbar. Wie können wir also eine Verbindung zwischen beobachteten molekularen Veränderungen der Erbinformation einerseits und den Auswirkungen auf die Fitness andererseits herstellen?

Einen relativ einfach zugänglichen Sonderfall von molekularen Veränderungen bilden Mutationen, die die Bauanweisung für einen in sich geschlossenen Baustein - insbesondere ein Eiweiß - zum Genom hinzufügen oder davon entfernen. Viele Eiweiße sind in ihren Funktionen gut untersucht. Wenn wir etwa wissen, dass an einem bestimmten Punkt in der Evolution eines Bakteriums mehrere Eiweiße neu hinzukamen, dann können wir versuchen, aus den bekannten Funktionen der Eiweiße auf die Auswirkungen dieses Ereignisses auf die Fitness des Bakteriums zu schließen. Diesem Weg ist unsere Arbeitsgruppe in Zusammenarbeit mit Kollegen in Großbritannien und Ungarn, insbesondere Professor Csaba Pal - in mehreren Veröffentlichungen nachgegangen. Im vorliegenden Artikel fasse ich diese Arbeiten für ein breiteres Publikum zusammen, insbesondere die Ergebnisse aus Pal et al. (2005) und Lercher und Pal (2008).

Wie kommt ein Genom zu solchen neuen Bausteinen? Dafür muss dem Genom ein Gen (hier: der Bauplan eines Eiweißes) hinzugefügt werden. Meist scheint einer von zwei Mechanismen im Vordergrund zu stehen: die Duplikation eines vorhandenen Gens mit anschließenden Veränderungen an den Details (der genauen Buchstabenfolge des Gens, und 

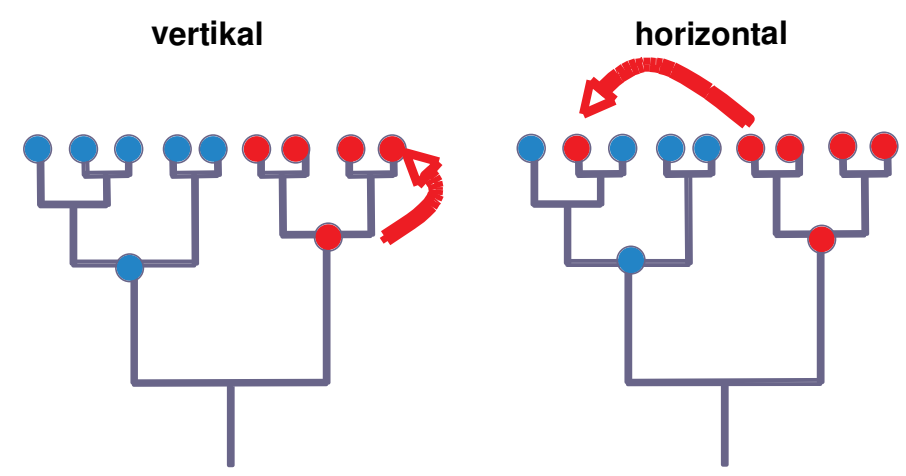

Abb. 1: Bei vertikalem Gentransfer wird die Erbinformation von den Vorfahren an die nächste Generation weitergegeben. Bei horizontalem Gentransfer wird Erbinformation von nicht-verwandten (oder entfernter verwandten) Organismen übernommen.

damit der Eigenschaften des entsprechenden Eiweißes) oder die Übernahme eines Gens von einem anderen Organismus (horizontaler Gentransfer; Abb. 1). Bei Bakterien steht Letzteres im Vordergrund. ${ }^{1}$ Bakterien verändern sich in ihrer Evolution häufig, indem sie fertige Bausteine einfach von anderen Bakterienarten übernehmen. Natürlich geschieht dies nicht gezielt. Ein möglicher Weg ist die Übertragung von Erbinformation durch bakterielle Viren: Statt der Erbinformation des Virus wird manchmal versehentlich ein Stück DNA der infizierten Zelle in eine Virushülle gepackt. ${ }^{2}$ Im Genom des Bakteriums erhalten bleiben nur solche horizontal transferierte Gene, die dem Bakterium einen Fitnessvorteil geben.

\section{Identifikation horizontaler Transfers}

Der horizontale Transfer von Genen tritt bei Bakterien häufig auf. Häufig ist jedoch relativ: Im Schnitt gewinnt ein Bakterium höchstens eine Handvoll Gene pro Jahrmillion. Eine direkte Beobachtung dieses Prozesses scheidet daher im Allgemeinen aus. Wir können jedoch die Gene heute existierender Bakterien vergleichen und daraus Rückschlüsse auf frühere Transfers ziehen. Dazu werden drei verschiedene Verfahren verwendet: ${ }^{3}$ (1) ein Vergleich der Buchstabenzusammensetzung einzelner Gene mit der in ihrem Genom ,üblichen“ (jede Bakterienart hat eine für sie typische Zusammensetzung); (2) ein Vergleich des Stammbaumes eines Gens mit dem Stammbaum der „Durchschnittsgene“; (3) ein Vergleich des Geninhaltes verschiedener verwandter Arten (wenn ein Gen in keinem einzigen nahen Verwandten vorkommt, ist es wahrscheinlich horizontal hinzugekommen). In unserer eigenen Forschung haben wir vornehmlich die letztere Methode verwendet (Abb. 3); die anderen beiden Methoden führen aber zu ähnlichen Ergebnissen.

Um aus dem Vorhandensein von Genen in verschiedenen Genomen auf die Evolutionsgeschichte der Gene zu schließen, benötigen wir eine Referenz: den Stammbaum der

\footnotetext{
1 Vgl. Lerat et al. (2005).

2 Vgl. Watanabe et al. (1968).

3 Vgl. Gogarten et al. (2002).
} 


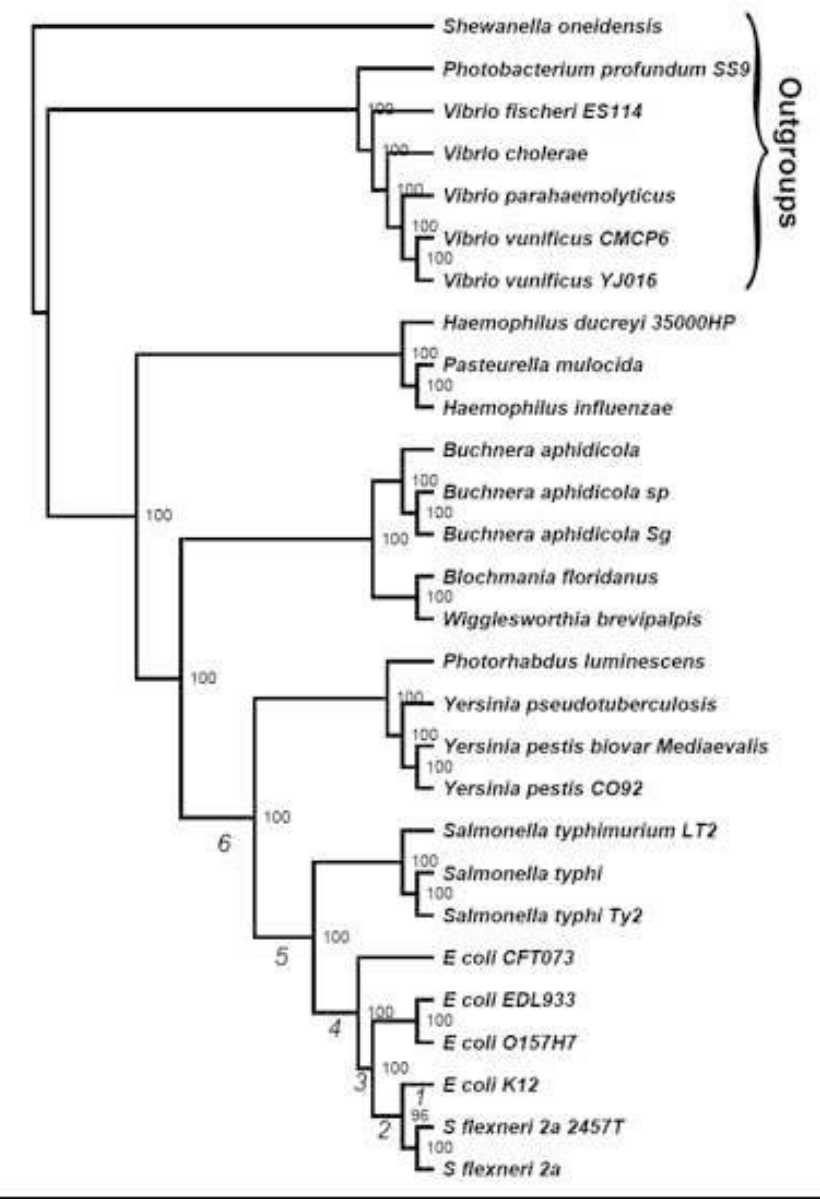

Abb. 2: Stammbaum von 28 gamma-Proteobakterien. Die Zahlen rechts von einzelnen Ästen geben deren Zuverlässigkeit (Bootstrap-Wert) in Prozent an. Zahlen unter einzelnen Ästen (1-6) geben ein relatives Alter an: „1" betrifft Ereignisse, die nach der Trennung der Linien von $E$. coli K12 und Shigella erfolgt sind und so weiter.

Bakterienarten, deren Gene wir analysieren. Dazu müssen wir zunächst so genannte orthologe Gene identifizieren: Das sind Gene in verschiedenen Arten, die alle vom selben Gen im gemeinsamen Vorfahren der Bakterien abstammen. Da sich die Buchstabenfolge ( $\mathrm{Se}$ quenz) der Gene in der Evolution nur langsam verändert, kann man orthologe Gene anhand ihrer Sequenzähnlichkeit identifizieren. Für die 28 gamma-Proteobakterien in Abbildung 2 findet man so beispielsweise mehrere Tausend Gruppen von orthologen Genen; darunter sind 47 Gruppen mit Vertretern in jeder einzelnen Art. ${ }^{4}$ Es ist wahrscheinlich, dass solche

4 Vgl. Lercher und Pal (2008). 


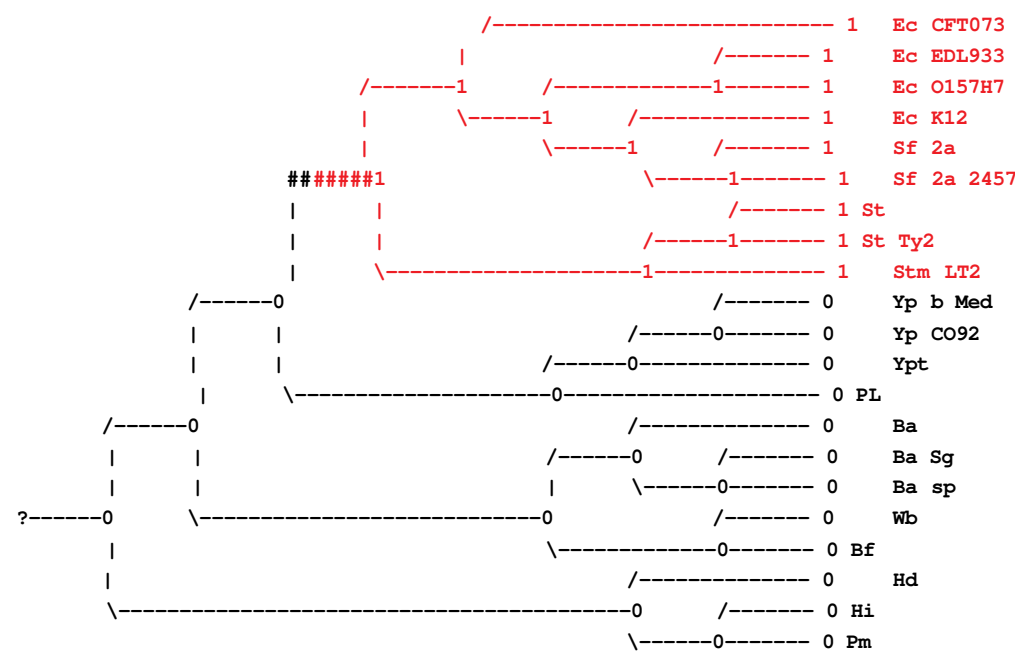

Abb. 3: An- und Abwesenheit von Genen einer orthologen Gruppe, dargestellt auf dem Stammbaum aus Abbildung 2. Eine „" " bedeutet Anwesenheit, eine „0“ Abwesenheit des Gens in der durch die Abkürzung gekennzeichneten Bakterienart (beziehungsweise in den namenlosen Vorfahren an den Verzweigungspunkten des Stammbaumes). Auf dem mit \#\#\#\# gekennzeichneten Ast ist ein Gen durch horizontalen Transfer hinzugewonnen worden: Nur die Nachfahren dieses Astes besitzen das Gen.

überall vorhandenen Gene selten horizontale Transfers durchmachen; ${ }^{5}$ daher eignen sie sich gut für die Bestimmung von Stammbäumen (die durch horizontale Transfers durcheinandergebracht werden). Je ähnlicher sich die Buchstabenfolgen von zwei Genen aus einer orthologen Gruppe sind, desto näher sind die beiden Bakterienarten, aus denen die Gene stammen, miteinander verwandt. Aus den Buchstabenfolgen kann man daher den Stammbaum der Bakterien rekonstruieren, wie in Abbildung 2 geschehen. ${ }^{6}$

Nun betrachten wir diejenigen orthologen Gruppen, die nicht in jeder Bakterienart einen Vertreter haben. Aufgrund des Musters, das durch die An- und Abwesenheit im Stammbaum entsteht, können wir vorhersagen, an welcher Stelle ein horizontaler Transfer (oder ein Genverlust) stattgefunden hat (Abb. 3). Auf diese Art konnten wir für den Stammbaum in Abbildung 2 mehrere Tausend horizontale Transfers identifizieren. ${ }^{7}$

\section{Das metabolische Netzwerk als Testfall}

\section{Allgemeine Fragestellungen}

Das Interesse unserer Arbeitsgruppe liegt nicht vornehmlich in der Analyse der Geschichte einzelner Eiweiße, auch wenn solche Beispiele unser Verständnis der Evolution bereichern. Wir suchen nach allgemeinen Mustern und Trends in evolutionären Vorgängen. Unsere Aufgabe besteht also zunächst darin, entsprechende Fragen zu formulieren: Fra-

\footnotetext{
5 Vgl. Ciccarelli et al. (2006).

6 Vgl. Lercher und Pal (2008).

7 Vgl. Lercher und Pal (2008).
} 
gen, die zwischen verschiedenen allgemeinen Hypothesen über die evolutionäre Gewinnung beziehungsweise den Verlust von Genen unterscheiden können - und die mit den verfügbaren Daten auch tatsächlich beantwortet werden können.

Einige Hypothesen über die Ursache evolutionärer Veränderungen von metabolischen Netzwerken lassen sich grob in zwei Gruppen einteilen: solche, die umgebungsspezifische Veränderungen betreffen, etwa die Anpassung an eine Veränderung der verfügbaren Nährstoffe, und solche, die die Eigenschaften des Netzwerkes unabhängig von Umgebungen betreffen. Solche umgebungsunabhängigen Eigenschaften sind etwa die Effizienz, mit der eine wichtige Umwandlung von Bausteinen durchgeführt werden kann, oder die Robustheit des Netzwerkes gegen den Ausfall einzelner Komponenten. Zwischen diesen beiden Klassen von Hypothesen können wir auch tatsächlich unterscheiden. Wir betrachten dazu alle Gene von E. coli, die durch horizontalen Transfer in dieses Genom (beziehungsweise dessen Vorfahren) gekommen sind. Wenn die meisten dieser Gene in der Mehrzahl aller Umgebungen, in denen $E$. coli leben kann, funktionell wichtig sind, dann können wir daraus schließen, dass Veränderungen des Genoms vornehmlich zu umgebungsunabhängigen Verbesserungen der Fitness führen (beziehungsweise durch diese motiviert sind). Finden wir umgekehrt, dass die meisten dieser Gene nur in sehr wenigen möglichen Umgebungen überhaupt benötigt werden, dann können wir daraus folgern, dass die Anpassung an neue beziehungsweise veränderte Umgebungen die wesentliche Motivation für Veränderungen des Genoms darstellt.

\section{Analyse des metabolischen Netzwerkes von E. coli}

Welche Gene sind in welchen Umgebungen von funktioneller Bedeutung? So allgemein ist die Frage kaum zu beantworten, ohne eine unrealistische Vielzahl von aufwändigen Experimenten durchzuführen. Einen Eindruck vermittelt jedoch die Analyse eines Teilsystems des Bakteriums. Das metabolische Netzwerk besteht aus allen Eiweißen von E. coli, die an der Herstellung der Grundbausteine für die nächste Bakteriengeneration beteiligt sind: Transporter, die Nährstoffe in die Zelle bringen, sowie Enzyme, die diese schrittweise verarbeiten. Der Vorteil dieses Systems: Die Funktionen der einzelnen Eiweiße sind aus zahlreichen biochemischen Experimenten gut bekannt. ${ }^{8}$ Das System als Ganzes ist - jedenfalls im Modellorganismus E. coli K12 - gut verstanden, und es gibt Simulationsmethoden, die die Umwandlung von Nährstoffen in Grundbausteine realitätsnah simulieren können. ${ }^{9}$

Wir benutzen die so genannte Flux-Balance-Analyse (FBA). ${ }^{10}$ In diesem Verfahren wird das metabolische Netzwerk zunächst als System von linearen Gleichungen dargestellt, in dem die Variablen Flüsse durch Reaktionen sind: Jede dieser Variablen gibt an, mit welcher Rate (Geschwindigkeit) eine bestimmte biochemische Reaktion abläuft. Für jedes im Bakterium vorkommende „einfache“ biochemische Molekül (Metabolit) gibt es nun eine Gleichung, die angibt, wie viel vom Metaboliten pro Zeiteinheit hinzukommt (mittels Flüssen durch Reaktionen, die den Metaboliten erzeugen), und wie viel wieder entfernt wird (mittels Flüssen durch Reaktionen, die den Metaboliten weiterverarbeiten). Ebenfalls Bestandteil der Gleichungen sind Gewinne und Verluste von Metaboliten durch Transport-

\footnotetext{
8 Vgl. Price et al. (2004).

9 Vgl. Palsson (2006).

${ }^{10}$ Vgl. Price et al. (2004).
} 
prozesse (von Nährstoffen in die Zelle hinein, von Abfallstoffen aus der Zelle heraus). Jede Gleichung beschreibt also, wie sich eine bestimmte Metabolitenkonzentration mit der Zeit verändert.

Die FBA macht nun zwei - biologisch sinnvolle - Annahmen. Die erste Annahme ist die eines Gleichgewichtszustandes: Die Konzentration aller internen Metaboliten verändert sich im Lauf der Zeit nicht, sondern Veränderungen finden nur außerhalb des Netzwerkes statt - als Aufnahme von Nährstoffen einerseits und als Abgabe von Abfallstoffen und der fertigen Grundbausteine für eine neue Zelle andererseits. Die zweite Annahme betrifft die Funktion des metabolischen Netzwerkes: Wir gehen davon aus, dass das Netzwerk durch Evolution gebildet und verfeinert wurde, um möglichst hohe Wachstumsraten des Bakteriums zu ermöglichen. Präziser: Bakterien mit effizienteren metabolischen Netzwerken, die dadurch pro Zeiteinheit mehr Grundbausteine (in der richtigen Zusammensetzung) herstellen konnten, hatten einen Vorteil gegenüber langsamer wachsenden Bakterien. Sie konnten dementsprechend mehr Individuen für die nächste Generation stellen und haben so die langsamer wachsenden Bakterien im Laufe der Evolution verdrängt. Wir nehmen daher an, dass das aus dieser Evolution resultierende, uns bekannte Netzwerk dahin gehend optimiert ist, möglichst hohe Wachstumsraten des Bakteriums zu ermöglichen. Um zu verstehen, wie die einzelnen Transporter und Enzyme des Netzwerkes eingesetzt werden, suchen wir also die Verteilung von Flüssen durch das Netzwerk (das heißt von realisierten Reaktionsraten), die zu einer maximalen Produktionsrate von Grundbausteinen (Biomasse) führen.

Die zwei skizzierten Annahmen formulieren ein mathematisches Problem. Die Gleichgewichtsbedingung formuliert ein lineares Gleichungssystem mit circa 1.000 Gleichungen. Die Bedingung maximaler Wachstumsrate formuliert nun ein Optimierungsproblem: Wir suchen die Flussverteilung, für die die Wachstumsrate (das heißt der Fluss von Grundbausteinen aus der Zelle heraus) maximal wird. Solche Optimierungsprobleme werden in der numerischen Mathematik seit langem betrachtet, und es gibt im Rahmen der ,linearen Programmierung“ gut entwickelte und effiziente Methoden, um sie zu lösen.

\section{Transfers in das metabolische Netzwerk}

Wir betrachten also jetzt alle Transfers in das metabolische Netzwerk von E. coli, die wir mit unseren Mitteln identifizieren können, und fragen für jedes dieser Gene: In wie vielen Umgebungen hat der durch das Gen codierte Transporter beziehungsweise das durch das Gen codierte Enzym überhaupt eine Funktion? Diese Frage können wir beantworten, indem wir für jede mögliche Umgebung (das heißt jede Nährstoffkombination, in der $E$. coli leben kann) fragen: Verändert sich die maximale Wachstumsrate, wenn das gerade betrachtete Gen entfernt wird und das Netzwerk ohne das von diesem Gen codierte Eiweiß auskommen muss? Nur wenn das der Fall ist, hat das Gen in dieser Umgebung eine wichtige Funktion. Abbildung 4 zeigt das Ergebnis unserer Analyse. ${ }^{11}$ Während nichttransferierte Gene des metabolischen Netzwerkes im Schnitt in fast der Hälfte aller Umgebungen wichtig für die Funktion des Netzwerkes sind, gilt dies nur für gut zehn Prozent der erst kürzlich durch horizontalen Transfer hinzugekommenen Gene. Kurz gesagt: Horizontal transferierte Gene sind - zumindest anfänglich - typischerweise umgebungsspezifisch.

\footnotetext{
${ }^{11} \mathrm{Vgl}$. Pal et al. (2005).
} 


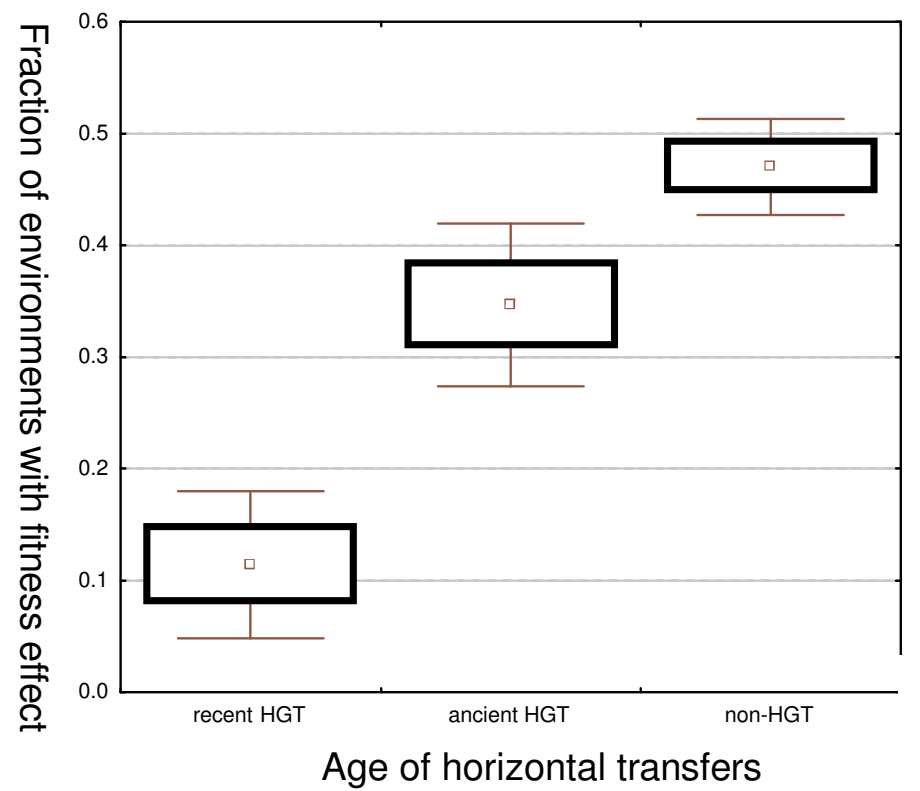

Abb. 4: Anteil der Nährstoffkonzentrationen, in denen die Entfernung eines Gens zu verminderter Wachstumsrate führt, für kürzlich hinzugewonnene Gene (recent HGT), alte Transfers (ancient HGT) und nicht-transferierte Gene (non-HGT).

Welche Funktionen führen diese neuen Gene aus? Natürlich ist diese Frage für jedes einzelne Gen unterschiedlich zu beantworten. Wir können jedoch auch hier wieder einen Schritt zurücktreten und das Ganze von einer abstrakteren Ebene aus betrachten. Wo liegen die Eiweiße im Netzwerk, relativ zum Netzwerkrand (wo es mit der Umgebung korrespondiert) und zum Netzwerkzentrum (wo es die fertigen Bausteine abliefert)? Abbildung 5 gibt die Antwort: Während weniger als zehn Prozent der zentralen, Biomasse produzierenden Reaktionen von Enzymen katalysiert werden, die durch horizontalen Gentransfer hinzugekommen sind, bestehen die Transporter zu fast zwei Dritteln aus horizontal transferierten Genen. ${ }^{12}$ Nach Abbildung 3 überrascht das nicht: Wenn es die Anpassung an Umgebungen ist, die Gentransfers erfolgreich macht, dann ist es wahrscheinlich, dass die Funktion der betroffenen Gene an der Schnittstelle des Bakteriums mit der Umgebung liegt. Neue Nährstoffe müssen häufig von neuen Transportern in die Zelle gebracht werden. Auf der anderen Seite hängen die Grundbausteine, die das Netzwerk produzieren muss, nicht von der Umgebung ab - die zentralsten Reaktionen sind deshalb im Laufe der Evolution stabil und verändern sich nicht so schnell durch Transfers.

${ }^{12}$ Vgl. Pal et al. (2005). 


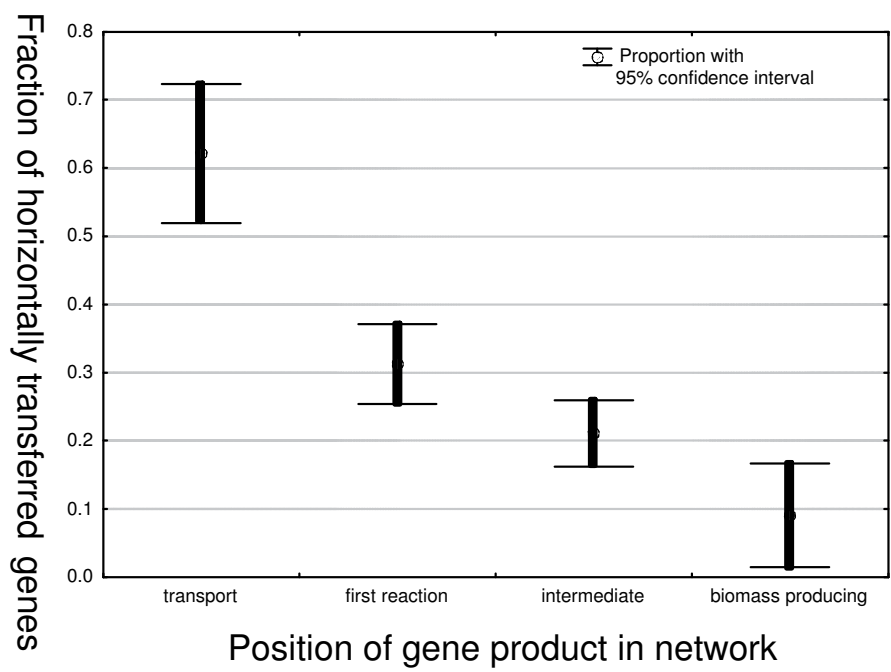

Abb. 5: Anteil horizontal transferierter Gene an allen Genen in verschiedenen Netzwerkpositionen: Transporter (transport); erste Reaktionen nach dem Transport (first reaction); mittlere Reaktionen (intermediate); Reaktionen, deren Produkte teilweise zu den zu produzierenden Grundbausteinen (Biomasse) gehören (biomass producing).

\section{Neue Gene müssen kontrolliert werden}

Wenn man eine neue Aufgabe erfüllen will (zum Beispiel den Transport eines neuartigen Nährstoffs in die Bakterienzelle durchführen), dann benötigt man zunächst das richtige Werkzeug (zum Beispiel den entsprechenden Transporter). Das allein ist aber nicht genug: Man muss auch wissen, wann und wie man das Werkzeug benutzt. Horizontal transferierte Gene müssen deshalb - wie andere Gene auch - kontrolliert werden: Sie müssen im richtigen Moment abgelesen werden, damit das von ihnen kodierte Eiweiß zur Verfügung steht (und - das ist eventuell weniger wichtig - sie müssen auch wieder ausgeschaltet werden, wenn sie gerade nicht benötigt werden). Wie wird nun ein neues Gen in das regulatorische Netzwerk eines Bakteriums integriert? Geschieht dies sofort (noch bevor sich ein neues Gen in der Bakterienbevölkerung durchsetzt), oder ist es ein langsamer Prozess (mit dem auch die Ururahnen noch beschäftigt sind)? Auch diesen Vorgang können wir kaum direkt beobachten. Aber wir können auch hier die Eigenschaften von alten Transfers mit denen von jungen Transfers vergleichen und so sehen, wie sich die Genregulation im Laufe der Zeit verändert.

\section{Anzahl der Regulatoren pro Gen}

Ein einfacher Ansatz liegt darin, die Anzahl von Regulatoren pro Gen zu vergleichen. Im Mittel werden Gene in $E$. coli von etwas weniger als einem einzigen uns bekannten Regulator kontrolliert (das heißt, es gibt eine bekannte Bindungsstelle für einen Transkriptionsfaktor). Ist diese Zahl konstant auch für horizontal transferierte Gene, unabhängig vom Alter des Transfers? Das ist nicht der Fall, wie Abbildung 6 zeigt: Erst kürzlich (das 


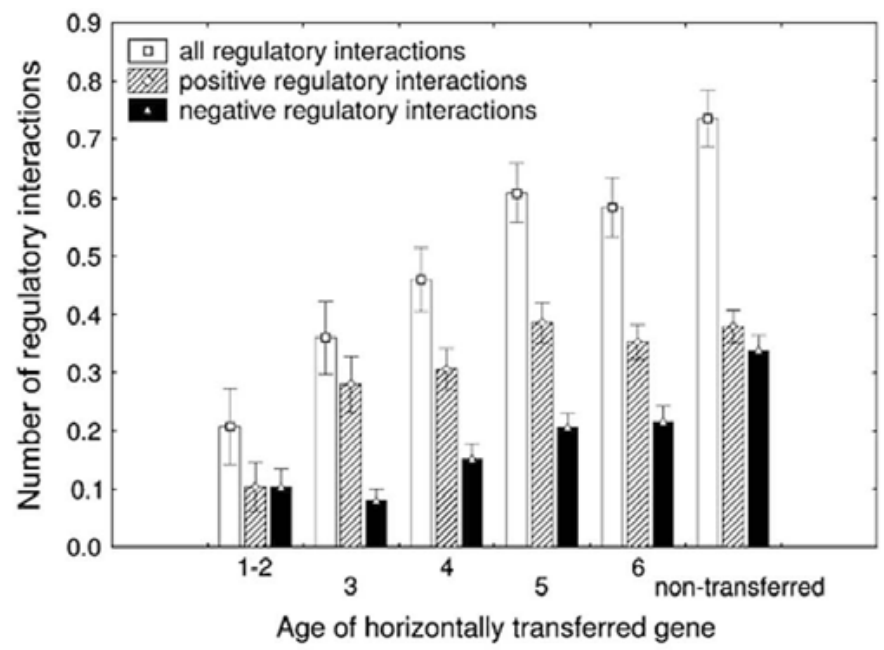

Abb. 6: Anzahl bekannter Regulatoren (Transkriptionsfaktoren) pro Gen, abhängig vom Zeitpunkt des Transfers (1-2 = sehr jung bis 6 = sehr alt; die Zeitskala ist aus Abbildung 2 ersichtlich). Offene Balken sind alle Regulatoren, schwarze Balken sind negative Regulatoren (die die Genexpression vermindern), schraffierte Balken sind positive Regulatoren (die die Genexpression erhöhen).

heißt innerhalb weniger Millionen Jahre) transferierte Gene haben im Schnitt erst etwa 0,2 bekannte Regulatoren pro Gen, kaum mehr als ein Fünftel dessen, was nicht-transferierte Gene aufweisen. ${ }^{13}$ Für positive Regulatoren - solche, die die Genexpression erhöhen wächst diese Zahl sehr schnell an und bleibt nach einigen Millionen Jahren etwa konstant. Ganz anders für negative Regulatoren: Hier steigt die Anzahl der Regulatoren pro Gen nur sehr langsam an und erreicht im von uns betrachteten Zeitraum (immerhin mehrere hundert Millionen Jahre) nie den Regulationsgrad, den man für nicht-transferierte Gene findet.

Das in Abbildung 6 visualisierte Ergebnis legt nahe, dass neue Gene nur sehr langsam in das regulatorische Netzwerk ihres neuen Genoms integriert werden. Während die positive Regulation, die die Verfügbarkeit des vom Gen kodierten Eiweißes sicherstellt, relativ schnell - innerhalb einiger Millionen Jahre - eingerichtet wird, dauert dies für die negative Regulation sehr viel länger. Aber können wir sicher sein, dass ,wenige Regulatoren pro Gen“ gleichbedeutend mit ,schlecht kontrolliert“ ist? Um diese (allerdings naheliegende) Vermutung zu überprüfen, führen wir einen zweiten Test durch.

\section{Parallele Regulierung von Partnern}

Wenn zwei Eiweiße in ihrer Funktion aufeinander angewiesen sind, dann liegt es nahe, dass sie parallel kontrolliert werden: Es ist (aus funktioneller Sicht) nur sinnvoll, das eine Eiweiß verfügbar zu machen, wenn gleichzeitig auch das andere verfügbar ist. Das ist

\footnotetext{
${ }^{13}$ Vgl. Lercher und Pal (2008).
} 
so strikt nicht richtig. Die Kontrolle des Zellzyklus, die unter anderem den Zeitpunkt der Zellteilung bestimmt, beruht teilweise darauf, dass komplexe molekulare Maschinerien aus vielen Eiweißen ständig verfügbar sind - nur ein einzelnes (aber essenzielles) „Zahnrädchen" wird erst im letzten Moment verfügbar gemacht, so dass die Maschinerie dadurch sehr präzise ,,an- und abgeschaltet" werden kann. ${ }^{14}$ Wir erwarten also keine exakte Parallelität zwischen der Kontrolle von funktionellen Partnern.

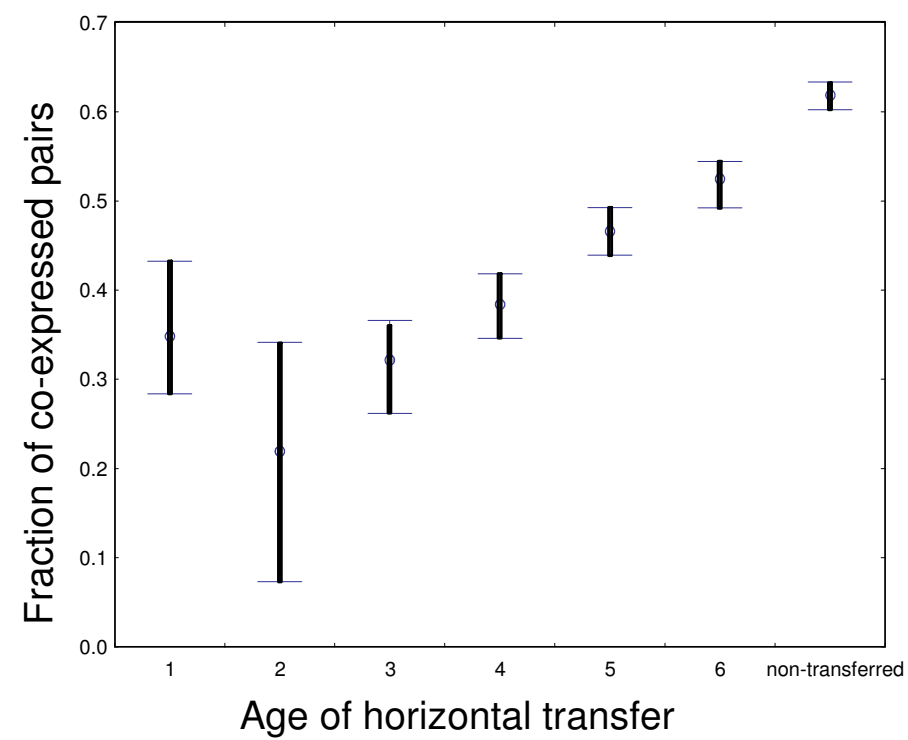

Abb. 7: Anteil von interagierenden Eiweißpaaren, die parallele Genexpressionsmuster aufweisen, in Abhängigkeit vom Alter der jeweiligen horizontalen Transfers ( $1=$ sehr jung, $6=$ sehr alt).

In vielen Fällen bleibt unsere Erwartung aber richtig, wie Abbildung 7 zu entnehmen ist: ${ }^{15}$ Knapp zwei Drittel aller zusammenarbeitenden Eiweißpaare, in denen (unseres Wissens) beide Partner nie horizontal transferiert wurden, sind gut koreguliert (das heißt, die Kopienzahlen werden parallel hoch- und heruntergeregelt). Für zusammenarbeitende Paare, bei denen eines der beiden Gene erst ,kürzlich“ (in den letzten wenigen Millionen Jahren) durch horizontalen Transfer in E. coli gelangt ist, sieht das anders aus: Hier ist nur etwa ein Drittel der Paare gut koreguliert (Abb. 7). Im Laufe der Jahrmillionen scheint sich die Koregulation aber zu verbessern: Paare mit sehr alten horizontal transferierten Genen sind beinahe so gut koreguliert wie nicht-transferierte Paare.

\section{Zusammenfassung und Ausblick}

Wir sind der Frage nachgegangen, welche Umstände massive Veränderungen von molekularen Systemen vorantreiben - indem wir die Eigenschaften von Genen untersucht haben,

\footnotetext{
${ }^{14}$ Vgl. Jensen et al. (2006).

15 Vgl. Lercher und Pal (2008).
} 
die im Laufe von Jahrmillionen durch horizontalen Transfer neu zum Genom des Modellorganismus E. coli hinzugekommen sind. Die Funktion neuer Gene ist meist auf einen kleinen Teil der verschiedenen Umgebungen beschränkt, in denen E. coli leben kann. Daher ist es wahrscheinlich, dass die Anpassung an diese speziellen Umgebungen die treibende Kraft hinter der Genakquisition war. Dazu passt, das horizontal transferierte Gene sich häufig am Rande des metabolischen Netzwerkes befinden - dem Teil, der für die Interaktion mit der Umgebung (zum Beispiel durch Transportprozesse) verantwortlich ist.

Neue Gene werden aber nicht sofort optimal in ein bestehendes System integriert. Ihre Kontrolle ist anfänglich rudimentär und scheint in vielen Fällen lediglich die Verfügbarkeit des vom Gen kodierten Eiweißes sicherzustellen. Die Feinjustierung der Genkontrolle die insbesondere dafür sorgt, dass das Gen nicht unnötig abgelesen wird - dauert viele Millionen Jahre. Die letzte Beobachtung ist besonders interessant. Nehmen wir einmal an, dass sich unsere Ergebnisse - die ausschließlich auf der Betrachtung horizontal transferierter Gene beruhen - auf alle Arten von Genen verallgemeinern lassen. Da die meisten natürlichen Umgebungen sich im Verlauf von Jahrmillionen wandeln, müssen sich die dort lebenden Organismen in ihrer Genkontrolle diesen Veränderungen anpassen. Wenn aber die Optimierung der Genkontrolle durch die Evolution länger dauert (bis zu mehreren hundert Millionen Jahren) als die Zeit bis zur nächsten Umgebungsveränderung, dann hinkt die Genkontrolle immer ihrem „Optimum“ hinterher. Wir könnten also vermuten, dass genetische Regulationssysteme fast immer damit beschäftigt sind, auf ein „,bewegliches Ziel“ hin zu steuern. Das würde unser Bild davon, wie Evolution abläuft (nämlich meist um ein stabiles Optimum herum), drastisch verändern.

\section{Literatur}

Ciccarelli, F. D., T. Doerks, C. von Mering, C. J. Creevey, B. Snel und P. Bork (2006). „Toward Automatic Reconstruction of a Highly Resolved Tree of Life“, Science 311, 1283-1287.

Gogarten, J. P., W. F. Doolittle und J. G. Lawrence (2002). „Prokaryotic Evolution in Light of Gene Transfer“", Molecular Biology and Evolution 19, 2226-2238.

Jensen, L. J., T. S. Jensen, U. de Lichtenberg, S. BrunAK und P. Bork (2006). „Co-Evolution of Transcriptional and Post-Translational Cell-Cycle Regulation“, Nature 443, 594-597.

Lerat, E., V. DAubin, H. Ochman und N. A. Moran (2005). „Evolutionary Origins of Genomic Repertoires in Bacteria“, PLoS Biology 3, e130.

LERCHER, M. J. und C. PAL (2008). „Integration of Horizontally Transferred Genes into Regulatory Interaction Networks Takes Many Million Years“, Molecular Biology and Evolution 25, 559567.

PAL, C., B. PAPP und M. J. Lercher (2005). „Adaptive Evolution of Bacterial Metabolic Networks by Horizontal Gene Transfer“, Nature Genetics 37, 1372-1375.

Palsson, B. O. (2006) Systems Biology: Properties of Reconstructed Networks. Cambridge.

Price, N. D., J. L. ReED und B. O. PALSSON (2004). „Genome-Scale Models of Microbial Cells: Evaluating the Consequences of Constraints“, Nature Reviews Microbiology 2, 886-897.

Watanabe, T., C. Furuse und S. SAKaizumi (1968). „Transduction of Various R Factors by Phage P1 in Escherichia Coli and by Phage P22 in Salmonella Typhimurium“, Journal of Bacteriology 96, 1791-1795. 
